\title{
Medicinal food understanding in Korean gastronomic culture
}

\author{
Serdar Oktay ${ }^{*}$ (D) and Erhun Kemal Ekinci
}

\begin{abstract}
Korean food has countless health benefits and has been used for centuries to keep the body in balance. Food and medicine are usually considered as one and the same thing. The idea that health starts with food means that medical treatment should be tried if any effect is not seen after trying to treat all diseases first with food. In order to help balance the body energies, there are five elements in these foods, namely fire, wood, water, metal, and earth. The dishes of the Korean people are synonymous with being healthy and delicious. Over the years, they have evolved from the culture, country's geography, and traditions of the people of the Korean peninsula under various effects. To keep the body warm and healthy, the Koreans have developed fermented foods that improve metabolism. Korean gastronomy has been established on healthy food. The Koreans do not eat food to become full. Foods are prepared and consumed to be healthy, healthy food is consumed in order to prevent diseases, and individuals who get sick aim to heal with foods and refer to using medications in case these methods are insufficient.
\end{abstract}

Keywords: Korean cuisine, Korean culture, Korean healthy foods, Korean gastronomic culture

\section{Introduction}

\section{Korean culture}

Korean history dates back to ancient times. The first Korean state was founded in $2333 \mathrm{BC}$. In near history, in 1948 , it took the name of the independent Republic of South Korea with the proclamation of the republic. Nowadays, the country has a successful liberal democracy. According to the 2017 data published by the World Bank, in the state with the capital in Seoul, the population is approximately 51.47 million and the annual income per capita is 29,000 US dollars. With an unemployment rate of $3 \%$, South Korea is among the countries with the lowest unemployment rate. The contribution of the successful education system implemented in the country to this low unemployment rate is great. With a surface area of $100,210 \mathrm{~km}^{2}$, Korea, which is surrounded by seas on three sides, has a climate with four seasons [1].

The Neolithic Age in the Korean peninsula is observed in $8000 \mathrm{BC}$. The transition to settled life and agriculture started in this period. Bitsalmunui pottery, which is the most important relic of the Polished Stone Age, was

\footnotetext{
* Correspondence: serdar.oktay@neu.edu.tr

Faculty of Tourism, Near East University, Neu avenue, 98010 Nicosia, Cyprus
}

discovered at the Amsadong archeological site in Seoul (Fig. 1). This pottery has a pointed base and a comb pattern on it. This relic proves that gastronomy in Korea is so ancient [2].

Nowadays, many religions live in peace in the Republic of South Korea. In Korea which got acquainted with Buddhism in $372 \mathrm{AD}$, there are many Buddhist temples. These temples formed a culture in the form of Korean temple food by adhering to their own beliefs.

In Korea, an alphabet called Hangul is used. The people speak Korean. The Hangul was created in 1444 by Sejong, a wise King of the Joseon dynasty. It is known as the most scientific and easy to learn alphabet in the world. The modern Korean etiquette, cultural norms, social behavior, superior Korean language, and dialectics emerged during the period of Joseon Kings [3].

Since the alphabet facilitates communication, Korea has become a country of culture, and this culture has become the reason why qualified human resources are raised by attaching great importance to education in the country. In South Korea, great importance is attached to people. Together with the high level of education, the Republic of Korea has passed the agricultural and industrial society and transformed rapidly into an information society [4]. 


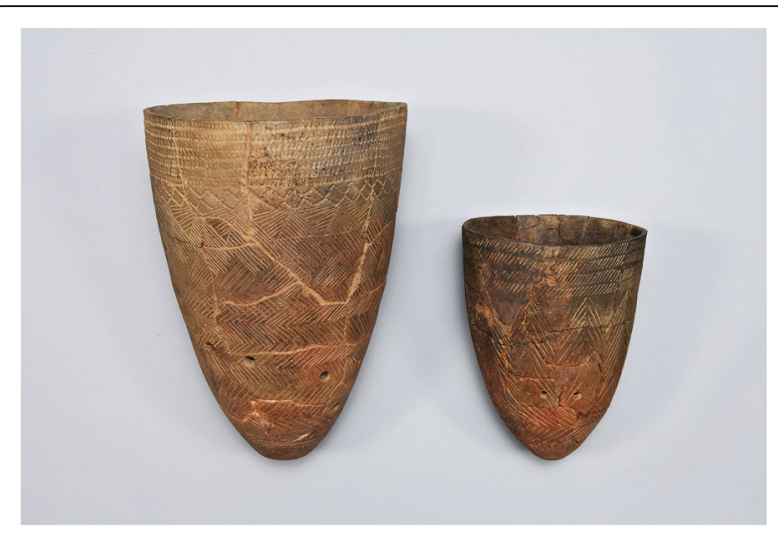

Fig. 1 Bitsalmunui Togi: the oldest pottery (bitsalmunui togi) is a simple "V"-shaped vessel, with a wide mouth and narrow base, and the entire surface is decorated with engraved lines and dots forming geometric patterns. Both the form and the decorative motifs that characterize this type of pottery are unique to Korea. Hence, Korean Neolithic culture is often referred to as the "Comb-pattern Pottery Culture"

According to our opinion, the value that is more important than the natural resources and richness of countries is educated and qualified human resource. Through the importance attached to skilled human resources, countries can make their economies stronger by achieving industrial progress without depending on natural resources.

\section{Defining gastronomy culture}

With its primary meaning, gastronomy is the branch of science that examines the relationship between food and culture. According to the famous French gastronome Savarin, gastronomy is the "Systematic analysis of everything related to human nutrition" [5]. According to another definition, "It is the discipline which includes all things consumed and called as foods, drinks, and nutrients" [6].

While examining the gastronomy of the country, the foods specific to that country should also be examined in the country's historical dimension. The gastronomy culture of a country also includes the historical and cultural characteristics of that country [7].

Regarding the factors that constitute the gastronomy culture, the gastronomy culture is defined as follows: the culture of eating and drinking is the values on which the nations reflect their own characteristics. Every society has taken a food culture from the society that existed before it, adopted a different food culture from each neighboring community, and received a food culture from those who migrated from other very distant geographies to the territory of their country. Thus, the gastronomy culture of that country has been formed [8].

The gastronomy culture has the property of including the cultural values of societies in the longest period. This characteristic is shaped according to the religious, agricultural, economic, and geographical features of societies [9].

Another definition of gastronomy culture is as follows: Food is one of the ways people define themselves as civilized. There is not a single food consumed by everyone on the Earth. Gastronomy is determined by the culture, anatomy, and genetic structure of people [10]. As a result of our study, in our opinion, the Korean gastronomy culture dates back to very ancient times and attaches importance to many philosophical values. The Koreans have a gastronomic culture which recognizes that it is possible to prevent diseases with food and to cure diseases by eating healthy foods.

\section{Methods/experimental}

In order to understand Korean medicinal food culinary culture, we investigate the Korean culture parts. In our research article, master's theses, doctoral dissertations, peer-reviewed journals, scientific research, scientific articles, printed books on cuisine culture, gastronomy books, official web publications, historical documents, translations, and archeological findings related to gastronomy were examined. The data we obtained were transformed into a whole by being classified and analyzed according to their content and characteristics. For the reliability of this research, resources of the Korean Ministry of Culture sports and Tourism ve Korean Culture and information service were taken into consideration.

\section{Result and discussions}

\section{Korean gastronomic culture and Korean medicinal foods}

The Korean people believe in the idea of Yak Sik Dong Won which means that the body-healing resources are the same as the sources of eating. This idea implies that health starts with food and that it is necessary to try medical treatment if any effect is not seen after trying to treat all diseases first with food (Fig. 2).

Korean cuisine has a history dating back to centuries. Since $300 \mathrm{BC}$, it has been greatly influenced by Chinese culture, particularly from medical aspects. According to the Taoist philosophy, health is a state of balance in which food selection is the key, and a person's body is healthy only when Yin-Yang and five elements are at equilibrium. Yin and yang are the energetic qualities that create the five elements (wood, fire, earth, metal, and water) with harmonious colors (green, red, yellow, white, and black) that shape everything in the universe, including our health (Table 1). Therefore, a traditional Korean table includes dishes or garnitures formed by five colors, most of which are low in calories and full of vegetables. Nowadays, the idea which promotes the consumption of five portions of fruit and vegetables and is also highly 


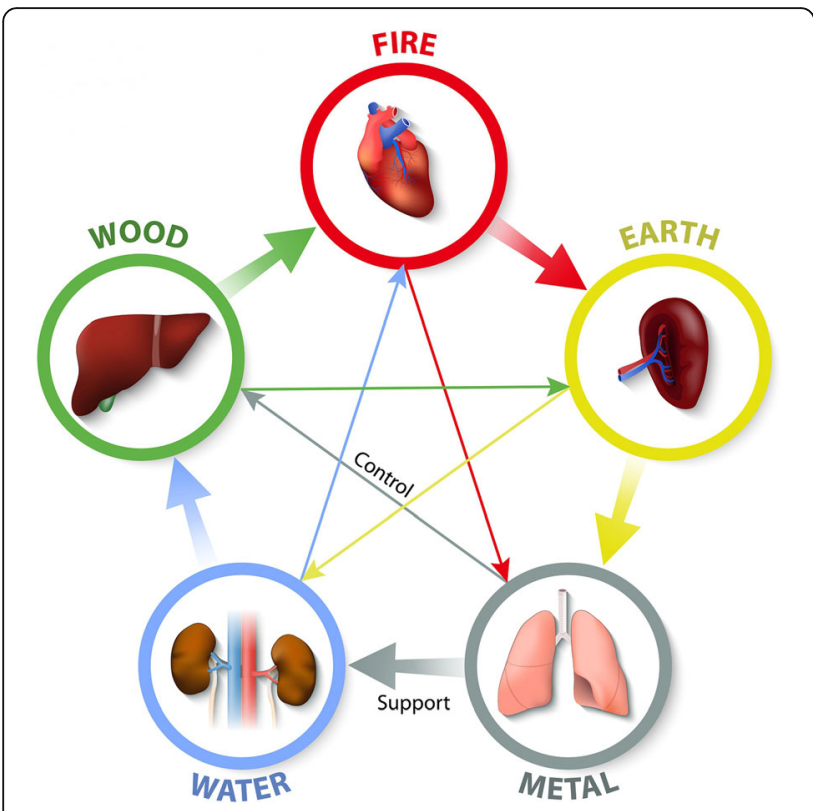

Fig. 2 Five elements' cycle balance imbalance. Each of the five elements, translated as wood, fire, earth, metal, and water, represents a different phase of the cycle. These phases can be used to understand health in a person's life. By using observations of how the five elements translate to human life physically, emotionally, and spiritually, a useful and effective tool to treat illness was developed

recommended in the international arena is a philosophy and tradition which is known from the ancient times in Korea [11].

In Korea, in addition to the yin and yang energy in the body, the senses of taste are used in order to keep the five basic elements, namely fire, wood, water, metal, and earth, in balance. The fire element is bitter, the wood element is sour, water is salty, metal is spicy, and earth is sweet [12]. It has been identified by scientific research that five flavors are associated with organs of the body. Sour food is good for the liver and gallbladder, bitter food is good for the heart and small intestine, sweet food is good for the stomach and pancreas, spicy foods are good for the lungs and large intestines, and salty foods are good for the kidneys and bladder. If one of your organs is ill, the food of the same element can help to repair the damage to that organ.

According to the ancient Chinese philosophy adopted by the Koreans, the five elements govern the evolution in the cosmos. These are wood, fire, earth, metal, and water. It is known that these elements can trigger and influence everything by working together. In cooking, the five elements correspond to the sour, bitter, sweet, spicy, and salty tastes. These flavors are related to five colors, respectively: blue/green, red, yellow, white, and black. Traditionally, a dish is prepared depending on how different flavors and colors contradict each other and how they comply with each other. For this dish to be successful, it is necessary to understand this harmony. Ordinary Korean women would naturally seek balance and harmony when preparing meals even if they had no knowledge of this theory. Careful consideration was the balance and harmony and also given to health depending on who would be eating the meal. [13]

The main principle that has a strong influence on the Korean mind and cooking method is yin and yang, in Korean, um and yang. This principle is the idea that two large opposing but interconnected forces manage everything in the universe and must always be in the balance of harmony.

There is a yin and yang balance in your body that you should care about to stay healthy. One way to do this is to eat food. If yang is high in your body, food that is yin should be preferred to compensate it. These foods must be in balance in the body and with other foods eaten. For example, the pork wrap is made with pork which is a yin food, and it is served with salted fermented shrimps which are yang in order to ensure balance [14].

The Korean food culture attaches importance to esthetic values besides superior healthy food philosophy. Basically, it is possible to collect these values in five categories: foods displaying the esthetics of harmonization and convergence, foods displaying the esthetics of waiting and patience, foods displaying the esthetics of care,

Table 1 Five elements' correspondences

\begin{tabular}{|c|c|c|c|c|c|}
\hline & Water & Wood & Fire & Earth & Metal \\
\hline Season & Winter & Spring & Summer & Late summer & Autumn \\
\hline Climatic Qi & Cold & Wind & Heat & Damp & Dryness \\
\hline Yang organ & Bladder & Gallbladder & Sm. intestine & Stomach & Lg. intestine \\
\hline Yin organ & Kidney & Liver & Heart & Spleen & Lung \\
\hline Sense organ & Ears & Eyes & Tongue & Mouth & Nose \\
\hline Body tissue & Bone & Sinews & Blood vessel & Muscles & Skin \\
\hline Emotion & Fear & Anger & Joy/shock & Worry & Sadness \\
\hline Color & Black & Green & Red & Yellow & White \\
\hline Taste & Salty & Sour & Bitter & Sweet & Spicy \\
\hline
\end{tabular}


foods displaying the esthetics of beauty in various colors, and foods displaying the esthetics of purifying. These values dealt with the characteristics of Korean foods in four categories also in the period of the Chosun Dynasty: food as a symbol of power, food as disease prevention and treatment, sharing love as a food, and food as an environment to communicate with the God. Going beyond material abundance, the core values of Korean food strive towards spiritual maturity, thinking of others, and a balanced life [15].

When it comes to the values embedded in Korean food, which has traditions that date back thousands of years, three things come to mind. The first is respect, the second is balance and harmony, and the third is health [13].

Koreans have discovered how foods are related to disease prevention and treatment. For this reason, while herbs and fruit such as ginger, cinnamon, adlay, wormwood, pomegranate, and ginseng are cooked as food, they are used for therapeutic effects [16].

In Korean cuisine, herbs are used for their medical values, and many common ingredients are agreed to have health benefits. For example, raw potato juice or chives are taken for the stomach. Garlic is used to cleanse the blood and help digestion. Hazelnut is good for skin and pregnant women. Bellflower roots are good for a cough and cold. Rice porridge and pine nuts are used in rehydrates to strengthen patients.

Ginseng is used as a food and medicine. There are several species of ginseng. Among these species, Korean ginseng is known as the most effective. Red ginseng is the most commonly used species for food and healing. Yellow ginseng, which is another species, is poisonous while fresh. Therefore, yellow ginseng is cooked with steam, and thus, the toxins in it are eliminated. It is used as a medication in treatment by being dried after cooking. Ginseng has been known for 5000 years. It is an antioxidant; it strengthens brain functions, energizes, and has aphrodisiac properties; and it is a plant root that is good for depression, anxiety, and digestive and respiratory disorders.

Another Korean healthy food product is soy. Since soy milk is energizing and increases the effect of what has been taken together with it, soybean milk used to be given to those who were sentenced to death by poisoning during the Joseon dynasty to ensure rapid death by increasing the effect of poison and reducing the prisoner's pain.

Since coconut oil has a calming and soporific effect and a numbing effect on the body when overused, it was also used to numb the patient during the treatment of the disease. Furthermore, it is known that Korean women make face masks with rice water to whiten their skin and not to get tanned in the sun.
Dried pollock fish, bean sprouts and tofu, and ginseng are used to regain the weak body energy.

In Korea, during the reign of the ancient kingdoms, a type of soil known as "Red Soil" used to be mixed with water and used for closing food containers. It is known that this soil gives the dish a sweet, bitter taste while cooking. Moreover, another soil type, which is known as "Yellow Soil," is known to be used to increase immunity against smallpox and for therapeutic purposes by mixing it with water.

Even diseases that appear to have external causes are ultimately observed as the products of internal factors. If a person is sufficiently strong to ward off the disease, he/she will not become sick even pathogens enter the body. Thus, treatment focuses primarily on strengthening the body's vital energy and increasing the body's ability to defend against the disease [17].

The most important feature of Korean cuisine is the fermentation method used to store and eat foods for a long time. The most known fermented foods include doenjang (soybean paste), ganjang (soy sauce), gochujang (hot pepper paste), and jeotgal (salted seafood). Jeotgal fermentation time ranges from several months to several years. It is also known that the acids and enzymes emerging from the fermented foods help the immune system, strengthen the liver, and balance the propagation of the beneficial bacteria necessary for intestinal health in the intestine.

Healthy and healing foods have a long history in Asian cultures. For a long time, eastern culture has believed that food and medicine come from the same source and lead to a healthier life by curing diseases [18].

Makgeolli, commonly known as rice wine, is a nutritious and light alcoholic beverage made from rice, barley, wheat, or malt. In makgeolli, nutrient components, such as organic acids, vitamin B, glutathione, and live yeast, provide potential antioxidants, immunomodulators, and anti-cancer activities. Traditional makgeol acts as a probiotic and has anti-diabetic and anti-obesity effects. Another traditional low alcoholic beverage Omegisool, which is another characteristic of Korea's Jeju island region, has recently been reported to contain probiotics, such as Lactobacillus and Pediococcus which have potential intestinal health effects. Another beverage, Sikhye, a traditional non-alcoholic beverage made from sticky rice fermented using Malt water, is usually taken after the meal to help digestion [19].

Makgeolli, which is made with a process during which steamed rice, barley, or wheat are mixed with malt and left to fermentation, is a light beverage with $6-7 \%$ alcohol content. Makgeolli, which is considered as a fermented beverage that is good for health, has started to attract attention in many parts of the world and has led to the emergence of Makgeolli brewing schools and well-trained waitresses who serve alcohol. 
Phyto-estrogens affecting mental and physical performance, ginseng, Ginkgo biloba, and green tea affecting cognitive functions, pharmacological functions of polyphenols, and the effects of caffeine on mental performance and mood are known [20].

Traditional healthy Korean foods cover antioxidant action mechanisms, anti-cancer, and aging characteristics. These have been supported by clinical and epidemiological evidence [21].

Kimjang means the job of making a sufficient amount of Kimchi to be eaten during the winter as a winter preparation, which is absolutely necessary for the Koreans. Kimchi, as one of the foods representing Korea, is often found on the dinner table of the Koreans as a side dish. Therefore, we can say that Kimjang is the most important job the Koreans do before the winter comes. Kimjang is a job that needs to be done seasonally in a detailed manner, and it is a process which lasts for 1 year. In the spring, various seafood brine, such as shrimp and anchovy brine, is prepared in every household. In the early summer, sun-dried sea salt is prepared, and at the end, hot pepper is dried, and its powder is prepared. In the autumn, when Kimjang time comes, people in the neighborhood gather and make kimchi with the prepared ingredients (Fig. 3). The Kimjang culture plays an essential role in increasing the sense of solidarity among the members of the society through gathering people and making a great amount of kimchi. The Kimjang culture, which reflects the distinctive food culture of the Koreans and the culture of sharing with a sense of solidarity in the society, was recorded on the UNESCO Intangible Cultural Heritage List on 5 December 2013. After the traditional kimchi-making season, it is aimed to prepare healthy foods from kimchi, which is fermented for a long time [22].

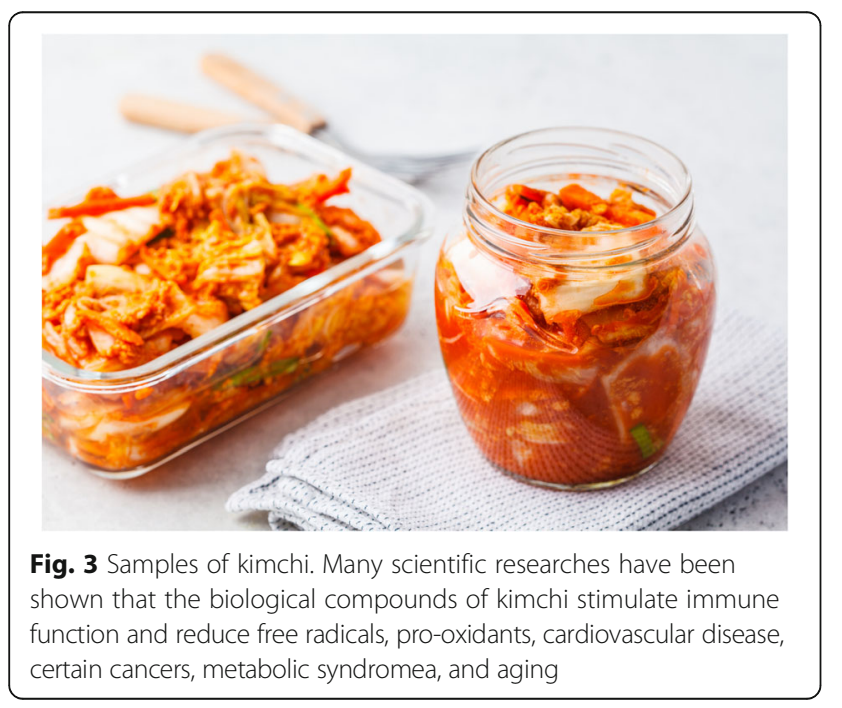

Kimchi is made with a variety of fermented vegetables such as a spicy traditional Korean garnish, Napa cabbage (baechu), hot red pepper, garlic, ginger, and other spices. For thousands of years, kimchi is served daily at every meal in Korean households. Kimchi has its own nutritional value and components, which are linked to health promotion and disease prevention. There are many varieties of kimchi [23].

When SARS, a severe acute respiratory disease, spread in the world in 2003, reports indicating that the Korean people were safe because they ate kimchi were published, and kimchi attracted the attention of the whole world. In 2006, the US health magazine, Health Magazine, selected kimchi as one of the five healthiest foods in the world. In America, healthy foods of Korean cuisine have created a new trend [24].

The number of Korean restaurants is increasing all over the world, including metropolitan cities such as Paris, London, and New York, and the evaluations of gourmets of Korean dishes are changing in a positive way. The number of Korean restaurants in Paris has reached a hundred. The most popular foods in restaurants in Paris are Bibimbap and Bulgoki. Especially bibimbap has gained an image of healthy food made from vegetables.

During the London Olympics held in July 2012, Baron Sebastian Coe, the president of the London Olympic Games Committee, hosted three hundred distinguished guests at a banquet arranged with Korean dishes in the Victoria \& Albert Museum, and the foods received high praise.

Most food safety events over the past two decades have occurred due to chemical, biological, and physical hazards and other sources. Food safety incidents involving chemical hazards are mainly caused by inedible, raw, non-food materials such as pesticides, heavy metals, drug residues, and sea toxins. Chemical hazards may also contain sweeteners, colorants, and the like food additives. For this reason, the Korean healthy food culture is gradually becoming more important [25].

Korea's traditional meal (bapsang) is generally made up of four constituents [13] (Fig. 4). Bap (cooked rice) provides calories, the main source of energy. Kuk (soup) allows people to chew and swallow rice, in turn supporting the digestive system. Previously, the word kuk was translated into soup; however, kuk is quite different from Western soup. Banchan (side dishes) make up the third element and make the food taste better to support digestion while replenishing the body with nutrition. Usually namul, legume, and fish comprise banchan. Jang (sauce, yangnyom), which stimulates peoples' appetites. Yangnyom includes herbs like garlic, green onions, red pepper, and onions. Unlike spices that are often used to cover or remove unpleasant smells of food, Korean yangnyom is used to enhance flavors and increase the health benefits of the foods it is combined with (Table 2). In the gastronomy culture of Korea, all the dishes are laid out in the middle of the table. 


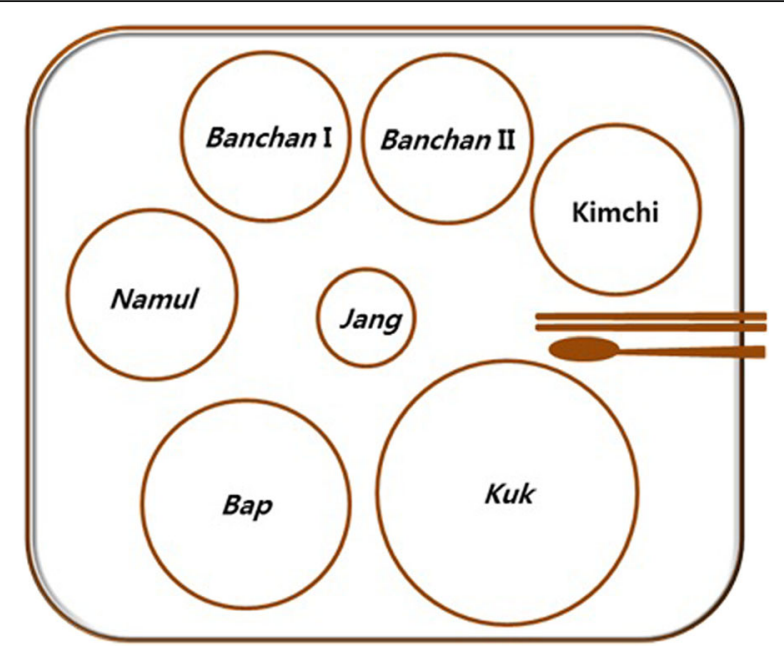

Fig. 4 Korea's traditional meals called bapsang. It is generally made up of four constituents. Bap is served alongside kuk, which assists in the swallowing and digestion of the food. In the bapsang, banchan is comprised of one type of kimchi, one namul, one vegetable dish (Banchan I), and one high protein dish (Banchan II), usually made from fish or meat as chim or gui. Jang or salted dishes, such as jangat-ji and jeotgal, are used to season food and stimulate one's appetite [13]

Jang (sauce, yangnyom), which stimulates peoples' appetites. Yangnyom includes herbs like garlic, green onions, red pepper, and onions. Unlike spices that are often used to cover or remove unpleasant smells of food, Korean yangnyom is used to enhance flavors and increase the health benefits of the foods it is combined with (Table 2). In the gastronomy culture of Korea, all the dishes are laid out in the middle of the table.

Examples of foods which demonstrate that food is good for health are as follows:

Jangguk-juk (porridge with soy sauce). This dish which is made by adding soy sauce to the porridge obtained by adding and boiling beef and shiitake mushroom to the soaked rice which is pestled is called jangguk-juk. It is rich in protein. It is a dish that is good for people who are ill or weak (Fig. 5a).

Another food is Kongkuksu (Korean pasta in bean juice). After soaking and boiling, soybeans are peeled and thoroughly ground and then eaten by putting Korean pasta on top of them. Since soybeans are rich in protein, they are qualified as "meat grown in soil" in Korea (Fig. 5b).

Bibimbap is said to be good for geriatric diseases nowadays, and it is considered to be a dish attracting attention worldwide (Fig. 5c).

$J u k$, which is made by boiling cereals with water for a long time, is a Korean-style porridge that is usually eaten by children or elderly people who have digestive problems (Fig. 5d).

The number of healthy foods, of which examples were given, is quite high. Korean cuisine is one of the most fascinating cuisines in the world nowadays. It includes sumptuous flavored and delicious pickles, Korean barbeque which is well-known for its rich flavored barbecues and red hot spicy stews, kimchi stew and spicy cucumber salad, Dungeness crab crepes, spicy octopus, ginseng chicken soup, traditional sweets, and teas such as five persimmon punch and ginseng tea [27].

\section{Korean medicinal foods \\ Juk}

$J u k$ is very popular to eat in Korea, and it comes in many different varieties. It is often eaten after a heavy meal like Korean BBQ or even when someone is sick. Due to its soft and moist texture it is easily digestible making it good food not only for sick people, but also for babies and the elderly. To add more of some restorative and medicinal qualities, Koreans like to add ginseng making it a power boosting meal (Fig. $5 \mathrm{~d}$ ).

\section{Kongnamulkuk}

Kongnamulkuk is just what to need to fight hangovers. Kongnamulkuk is cheap, extremely easy to make, and packed full of nutrition. The roots of the bean sprouts contain a special chemical called asparagines which helps get over hangovers very quickly. Kongnamulkuk is also useful for colds. The bean sprouts are rich in vitamin C, which boosts your immune system (Fig. 6a).

\section{Insam}

Insam or ginseng is a fleshy root herb used for thousands of years as a natural remedy for various illnesses. The ginseng has the ability to boost the nervous and immune system, strengthens and builds muscles, prevents stress, promotes brain activity, treats stomach disorders, prevents vomiting and nausea, enhances memory, strengthens lungs, can make you more resistant to sickness like cold and flu, treats postmenopausal symptoms in 
Table 2 Categories of Korean bapsang (Fig. 8) and representative Korean foods [26]

\begin{tabular}{|c|c|c|c|}
\hline Category & \multicolumn{2}{|c|}{ Subcategory } & Representative Korean foods (K-food) \\
\hline Bap & & & $\begin{array}{l}\text { Ssalbap (white rice, brown rice, black rice), boribap, kongbap, } \\
\text { okokbap, nurungji (sungnyung) }\end{array}$ \\
\hline \multirow[t]{2}{*}{ Kuk } & \multicolumn{2}{|l|}{ Kuk } & $\begin{array}{l}\text { Doenjangkuk, bukeokuk, kongnamulkuk, miyok-kuk, soegogimukuk, } \\
\text { torankuk }\end{array}$ \\
\hline & \multicolumn{2}{|l|}{ Chigae } & $\begin{array}{l}\text { Kimchichigae, doenjangchigae, cheongkukjangchigae, sundubuchigae, } \\
\text { oigamjeong }\end{array}$ \\
\hline \multirow[t]{10}{*}{ Banchan } & \multicolumn{2}{|l|}{ Kimchi } & $\begin{array}{l}\text { Baechukimchi (bossamkimchi), kkakdugi, oisobagi, chonggakkimchi, } \\
\text { mulkimchi (dongchimi, nabakkimchi), yeolmukimchi, gatkimchi }\end{array}$ \\
\hline & \multirow[t]{2}{*}{ Namul } & Saengchae & $\begin{array}{l}\text { Saengchae (radish, cucumber), juksunkyeojachae, buchumuchim, } \\
\text { dalraemuchim, miyokmuchim, paraemuchim }\end{array}$ \\
\hline & & Sukchae & $\begin{array}{l}\text { Kongnamul, sikeumchinamul, dorajinamul, kosarinamul, beoseotnamul, } \\
\text { aehobaknamul, gajinamul, chwinamul, naenginamul, gondrenamul, } \\
\text { meowideulkkaejeuptang, japchae, tangpyeongchae (mukmuchim), } \\
\text { gujeolpan }\end{array}$ \\
\hline & \multirow[t]{7}{*}{ Banchan } & Chim & Kalbichim, suyuk, saengseonchim, sundae, kaetnipchim \\
\hline & & Gui & $\begin{array}{l}\text { Kimgui, saengseongui, bulgoki, teok-Kalbi, bukeogui, deodeokgui, } \\
\text { borigulbi }\end{array}$ \\
\hline & & Jorim & $\begin{array}{l}\text { Saengseonjorim, soegokijangjorim, kongjaban, yeongeunjorim, } \\
\text { dubujorim }\end{array}$ \\
\hline & & Bokeum & $\begin{array}{l}\text { Myeolchibokeum, ojingobokeum, jeyukbokeum, teokboki, dakbokeum, } \\
\text { oibokeum (oibaetduri) }\end{array}$ \\
\hline & & Jeon & $\begin{array}{l}\text { Saengseonjeon, chaesojeon (squash, eggplant, burdock, shiitake), } \\
\text { hwauangjeok (pasanjeok), nokdubindaeteok, haemulpajeon, } \\
\text { buchujeon, dubumuchim, yukjeon }\end{array}$ \\
\hline & & Hoe & $\begin{array}{l}\text { Saengseonhoe, hongeohoe, kanghoe (green onions, water parsley), } \\
\text { dureupsukhoe }\end{array}$ \\
\hline & & Dried banchan & Bukak, ssam (loose leaf lettuce, perilla leaf, crown daisy) \\
\hline \multirow[t]{3}{*}{ Jang } & \multicolumn{2}{|l|}{ Jang } & Jang (doenjang, cheongkukjang, gochujang, kanjang) \\
\hline & \multicolumn{2}{|l|}{ Jeolim } & Jangachi \\
\hline & \multicolumn{2}{|l|}{ Jeotgal } & Jeotgal (sikhae) \\
\hline \multirow[t]{3}{*}{ Miscellaneous } & \multicolumn{2}{|c|}{ One-bowl food } & $\begin{array}{l}\text { Bibimbap, teokmandutkuk (teok-kuk, mandutkuk), kuksu } \\
\text { (naengmyeon, kalkuksu, kongkuksu, kuksujangkuk) }\end{array}$ \\
\hline & \multicolumn{2}{|c|}{ Teok, hankwa } & $\begin{array}{l}\text { Shaped teok (songpyeon), pounded teok (injeolmi), steamed } \\
\text { teok(baekseolki, ssukseolki, siruteok, jeungpyeon, yaksik), pan-fried } \\
\text { teok(hwajeon), boiled teok (gyeongdan), yakkwa, yugwa, dasik }\end{array}$ \\
\hline & \multicolumn{2}{|l|}{ Beverage } & Sikhye, sujeongkwa, omija-cha, hwachae \\
\hline
\end{tabular}

women, and treats diabetes, infections, headaches, and cancer. Due to its strong potent action, it is not recommended for those suffering from high blood pressure (Fig. 6b).

\section{Samgye-tang}

Samgye-tang is a bowl of hot broth with a whole chicken which is stuffed with glutinous rice, ginseng, jujube, ginkgo nut, and garlic. During the Korean summer season, people sweat a lot to cool down the body. However, by losing this internal heat, your appetite reduces and become more energyless. By eating this extremely nutritious dish, it replenishes the lost internal warmth in the body, hence giving people an energy boost. There is a saying in Korea that by fighting the heat you must fight it with heat as well. This is called "yi yeol chi yeol". Samgye-tang also has ginseng and other stamina- enhancing ingredients stuffed inside making it a restorative and energy-boosting meal (Fig. 6c).

\section{Kimchi}

Kimchi is fermented spicy cabbage and is the most famous Korean dish. Well-fermented kimchi is sour, so is beneficial to the gallbladder and liver. Kimchi has vitamins $\mathrm{A}, \mathrm{B}$, and $\mathrm{C}$, and it contains Lactobacillus, a probiotic similar to that found in yoghurt. Probiotics aid digestion, boost the immune system, help to efficiently use vitamins, and filter out bad bacteria or toxins. They are also linked to reducing cholesterol (Fig. 3).

\section{Doenjang paste}

Doenjang paste is a fermented soybean paste similar to miso. The fermentation process of the doenjang paste 


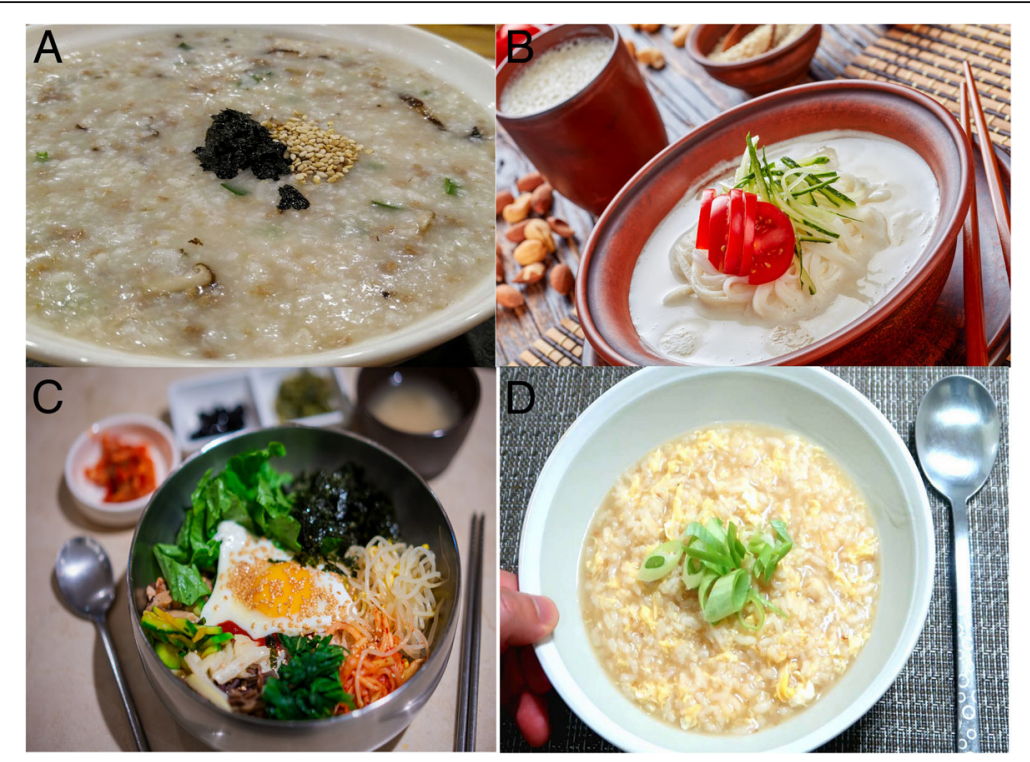

Fig. 5 Korean medicinal food examples. a Jangguk-juk: It is an ideal dish that is good for recovering ill, weak, elderly people. b Kongkuksu: Beans, which are the main ingredients of kongguksu, are filled with high-quality proteins, while the saponin in the beans can reduce cholesterol levels and help combat obesity. c Bibimbap's nutritional balance, which is said to help keep those who eat it free from geriatric diseases. $\mathbf{d}$ Juk is usually eaten by children or elderly people who have digestive problems

neutralizes the toxins and anti-nutrients that soybeans contain. Doenjang is salty in taste and is related to the kidneys and bladder. Doenjang is a cheap source of protein. Fermented soy paste, the most essential condiment of Korean cookery for more than 2000 years. It is rich in flavonoids, linolic acid, vitamins, minerals, and hormones. It is anti-cancer and prevents cardiovascular disease (Fig. 6d).

\section{San-Namul}

San-namul is the Korean word for vegetables gathered from mountains. Anything from the leaves, stems, and

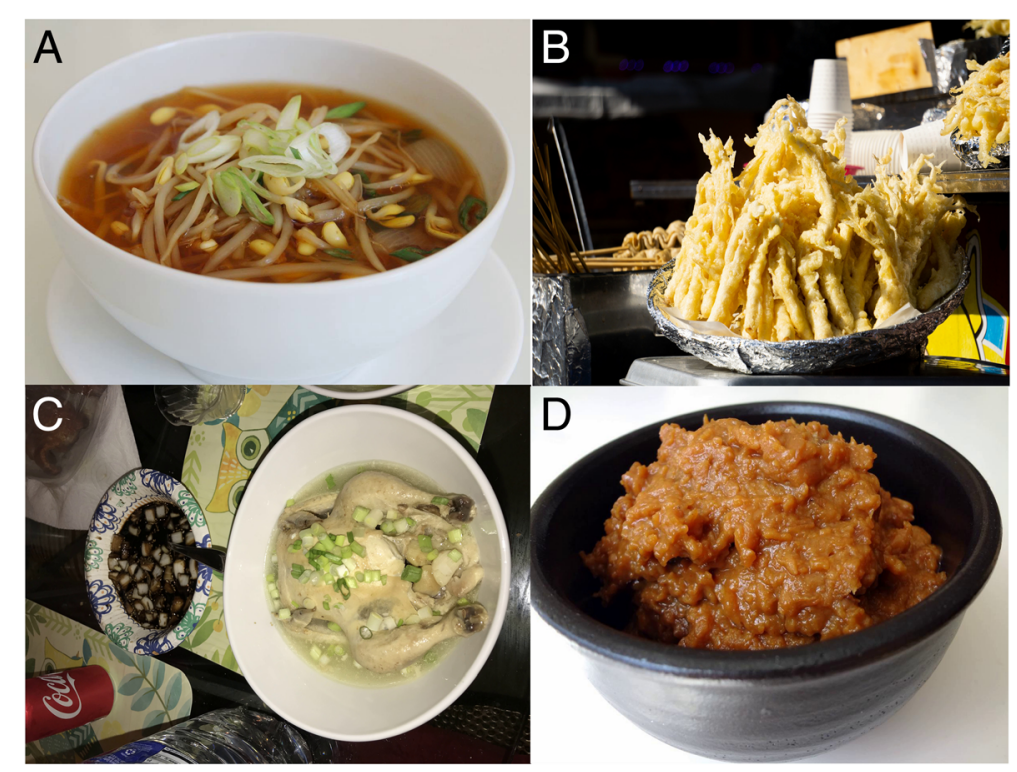

Fig. 6 Korean medicinal food examples a Kongnamulkuk: The soybean's roots of the sprouts contain lots of asparaginic acid, and it reduces the acetaldehyde that is formed after drinking alcohol. Kongnamulkuk soup has lots of vitamin C. So it is used for recovering from a cold. $\mathbf{b}$ Insam or ginseng: All over the world, ginseng is the herb of choice for boosting stamina. c Samgye-tang: It is a very popular summer stamina meal in Korea. $\mathbf{d}$ Doenjang paste is rich in essential amino acids. Linoleic acid has an important role in normal growth of blood vessels and prevention of blood vessel-related illness 

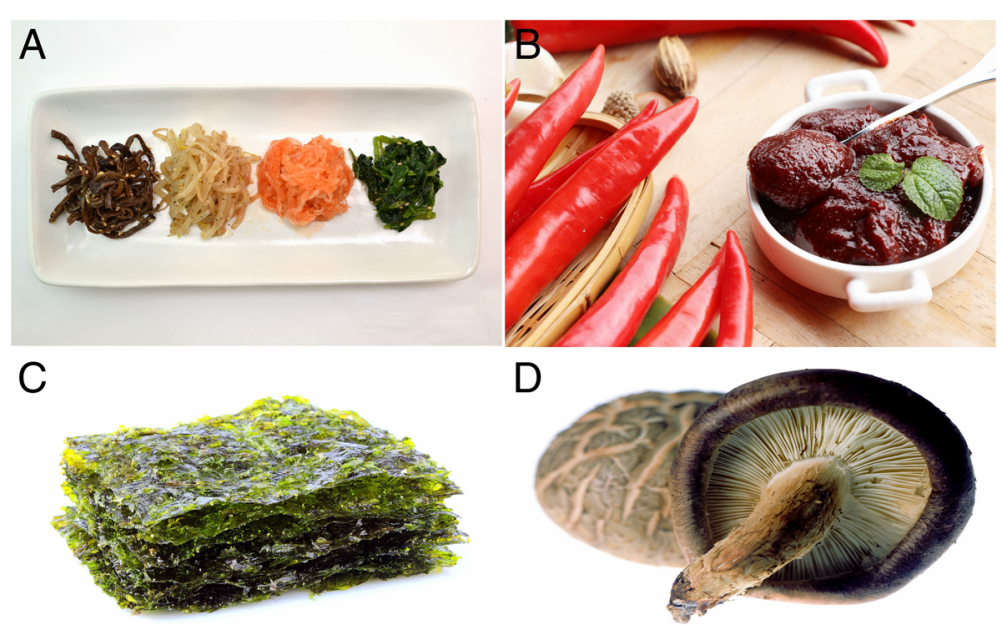

Fig. 7 Korean medicinal food examples. a San-namul is good for the heart and small intestine. b Gochujang is a probiotic, stimulates fat loss, increases metabolism, keeps your heart healthy, and decreases stress levels. c Gim or nori has vitamins, protein, and dietary fiber. It contains ingredients that help expel cholesterol from the body. $\mathbf{d}$ Pyogo is called the meat of the earth. It has rich nutritional value and low cholesterol and is an anti-cancer food

roots are used. Namul vegetables or herbs are often bitter, which is good for the heart and small intestine. They are often added to one of Korea's most famous dishes, bibimbap-a combination of rice, namul, kim (seaweed), fermented vegetables, and egg (Fig. 7a).

\section{Gochujang}

Gochujang is a hot spicy paste made from hot peppers and is found in a huge amount of Korean dishes. The spiciness of gochujang is good for the lungs and large intestine and is yang in energy. Gochujang has been a part of traditional Korean cuisine since the sixteenth century. Gochujang aids digestion so is great to eat with meat or food that is harder for the body to digest (Fig. 7b). Capsacin, a substance found in chili peppers, is known to reduce body fat. Gochujang is used in Korean dishes such as bibimbap (rice with vegetables), tteokbokki (rice cakes in hot sauce), gochujang stew, and bibimguksu (noodles with vegetables).

\section{Gim}

Gim, also known as nori, is a type of seaweed high in iron, magnesium, iodine, omega 3 , and vitamins $\mathrm{A}$ and C. It is usually seasoned with salt and toasted. Research suggests gim can help lower cholesterol levels. Gim is salty so is linked to the kidneys and gallbladder (Fig. 7c). Gim is used as a side dish and eaten with rice, is very popular with children in Korea, is used to make gimbap (similar to a nori roll), and is often sprinkled on top of rice dishes or udon noodles.

\section{Pyogo}

Pyogo is an edible mushroom originating from Northeast Asia (Fig. $7 d$ ). It contains high levels of vitamins $B_{2}$ and Niacin, an antitumor substance, as well as lentinane, which may reduce cholesterol. In Korean cuisine, the pyogo is widely used to enrich the taste of dishes.

\section{Yuja}

Yuja is a citrus fruit originating from the East Asia. Considered to be a hybrid of the wild mandarin and the Ichang lemon, the Yuja contains vitamin $C$ and three times more antioxidants than lemons (Fig. 8). It is used as a remedy for cold and winter illness. Koreans consume Yuja in a form of tea or as an ingredient in traditional desserts.

\section{Korean temple foods}

Korean temple foods consist of dishes made in Buddhist temples. Since Buddhist monks do not eat meat, they have developed a variety of cooking methods with soybeans or vegetables to eliminate protein deficiency. Nowadays, they are trendy among people who are vegetarian or dieters.

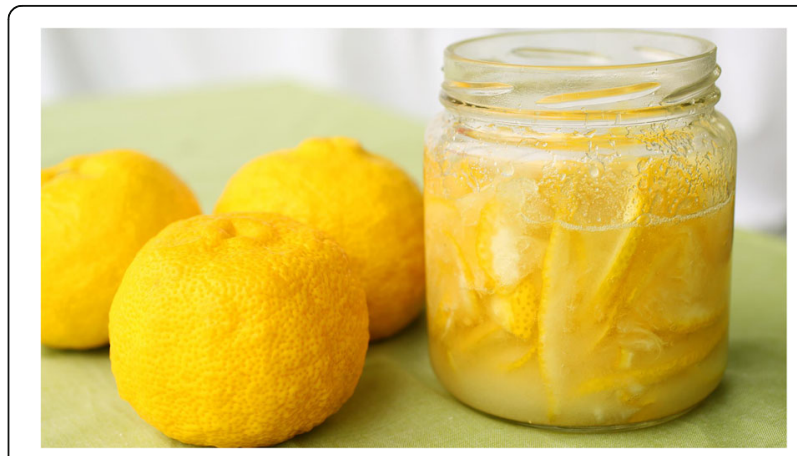

Fig. 8 Korean medicinal food examples. Yuja has three times more vitamin $C$ than lemon. Its uses are for a healthy skin, hair, and nails. Also, it is an antioxidant and boosts the body's immune system 
Currently, Korean temple foods apply the concept which is called from farm to table, by using the materials which are obtained only from farm animals or naturally grown and has a history of more than 1700 years, is ecofriendly and combined with clean nutrition awareness. The temple cuisine preserves the respect stance for life. Its recipes concretize its philosophy and conscience not only to feed the body but also to feed the soul [28].

In a scientific study conducted in 27 Korean Buddhist temples from 1997 to 2002, the medical effects of plants used as food were investigated. Medicinal plants were found out to be beneficial in digestive, circulatory, and respiratory diseases. These results demonstrate that foods consumed in Korean temples are highly therapeutic and are used in a variety of diseases [29].

\section{Conclusion}

In Korean gastronomic culture, food and medicine are usually considered as one and the same thing. The idea that health starts with food means that medical treatment should be tried if any effect is not seen after trying to treat all diseases first with food. To keep the body warm and healthy, the Koreans have developed fermented foods that improve metabolism.

The Korean medicinal food culture has been coming from the idea of Yak Sik Dong Won. This idea implies that health starts with food and that it is necessary to try medical treatment.

The Korean culinary culture preserves its aim of producing healthy food with traditional cooking methods, cooking technology, basic principles, and knowledge. The Koreans achieve these goals by using fermentation, boiling, blanching, seasoning, and pickling. Korean gastronomy has been established on healthy food. The Koreans do not eat food to become full. Foods are prepared and consumed to be healthy, healthy food is consumed in order to prevent diseases, and individuals who get sick aim to heal with foods and refer to using medications in case these methods are insufficient. In contrast to today's foods which are said to be good for health with fabrication and vague rumors, the Korean culinary culture has a structure that is proven and supported by medical and scientific data. During the preparation of foods, products in the content are consciously composed of products that have been proven to be good for health. This consciousness is based on the scientific background of the Korean culinary culture that has been developing for centuries.

\section{Acknowledgements}

Not applicable

\section{Authors' contributions}

The authors formed the article together. All authors read and approved the final manuscript.
Funding

The authors received no financial support for research, authorship, and/or publication of this article.

Availability of data and materials

Not applicable.

\section{Competing interest}

The authors declare that they have no competing interests.

Received: 7 March 2019 Accepted: 27 May 2019

Published online: 17 July 2019

\section{References}

1. Kyung Moon Hwang. Kore Tarihi. Istanbul: Feylesof Yayınevi; 2018.

2. Thomas Bale M. Storage practices, intensive agriculture, and social change in Mumun pottery period Korea, 2903-2450 calibrated years B.P. PhD thesis. Toronto: Philosophy Department of Anthropology University of Toronto; 2011.

3. Esendemir A. Asialogy Kore Alfabesi. Istanbul: Cinius Yayınevi; 2017.

4. de Mente BL. The Korean mind: understanding contemporary Korean culture. Vermont: Tuttle Publishing; 2012.

5. Savarin JAB. The physiology of taste. UK: Penguin Books; 1994.

6. Rosario Scarpato. Gastronomy studies in search of hospitality. J Hosp Tour Manag. 2002;9(2):17-9.

7. Serdar Oktay, Saide Sadıkoğlu. Gastronomic cultural impacts of Russian, Azerbaijani and Iranian cuisines. Int J Gastron Food Sci 2018; 12, 6-13. doi. org/https://doi.org/10.1016/j.ijgfs.2018.03.003.

8. Serdar Oktay, Saide Sadıkoğlu. The gastronomic cultures' impact on the African cuisine. J Ethn Foods. 2018. p. 1-7. doi.org/https://doi.org/10.1016/j. jef.2018.02.005.

9. Serdar Oktay. Study on gastronomic cultures of post-Neolithic civilizations in Anatolia. J Culinary Sci Technol 2018; doi.org/https://doi.org/10.1080/ 15428052.2018.1489322.

10. Civitello L. Cuisine and culture: a history of food and people. New Jersey: Wiley; 2007.

11. Korean Ministry of Culture, Sports and Tourism Kore Gerçeği: Kore'nin Dünü ve Bugünü Korea: Korean culture and information service; 2015.

12. Andrew C. Nahm. Kore Tarihi ve Kültürü. Izmir: Ege Universitesi Basımevi; 1998.

13. Dae Young Kwon, Soon Hee Kim, Myung Sunny Kim, Myoung Sook Lee, Yong Soon Park, Hae Jeong Lee, Soon-ah Kang, Hyun Sook Lee, Kyung-Eun Lee, Hye Jeong Yang, Min Jung Kim, Young-Eun Lee. Korean diet: characteristics and historical background. J Ethnic Foods Volume 3, Issue 1, March 2016, Pages 26-31. doi.org/https://doi.org/10.1016/j.jef.2016.03.002.

14. Maangchi. Maangchi's real Korean cooking: authentic dishes for the home cook. NYC: Rux Martin book/Houghton Mifflin Harcourt; 2015.

15. Hae-Kyung Chung, Hye Jeong Yang, Dayeon Shin, Kyung Rhan Chung. Aesthetics of Korean foods: the symbol of Korean culture. J Ethnic Foods 2016; 3. dx.doi.org/https://doi.org/10.1016/j.jef.2016.09.001.

16. Park K-Y, Young Kwon D, Lee KW, Park S. Korean functional foods: composition, processing and health benefits. FL: CRC Press; 2018.

17. Hur I-h. Korean medicine: a holistic way to health and healing. Seoul: Korean Essentials Publish; 2013.

18. Shi J, Ho C-T, Shahidi F. Functional foods of the east (nutraceutical science and technology). FL: CRC Press; 2010.

19. Digar Singh, Sunmin Lee, Choong Hwan Lee. Metabolomics for empirical delineation of the traditional Korean fermented foods and beverages. Trends Food Sci Technol 2017; 61, 103-115. dx.doi.org/https://doi.org/10. 1016/j.tifs.2017.01.001.

20. Watson D. Performance functional foods. London: Woodhead Publishing; 2003

21. Shi J, Shahidi F, Ho C-t. Asian functional foods. FL: CRC Press; 2005.

22. Chun L, Massov O. The kimchi cookbook: 60 traditional and modern ways to make and eat kimchi. CA: Ten Speed Press Berkeley; 2012.

23. Nobuko Hongu, Angela S. Kim, Asuka Suzuki, Hope Wilson, Karen C. Tsui, Sunmin Park. Korean kimchi: promoting healthy meals through cultural tradition. J Ethnic Foods 2017; 4. dx.doi.org/https://doi.org/10.1016/j.jef.2017.08.005.

24. Hong D, Rodbard M. Koreatown: a cookbook. NYC: Clarkson Potter publish; 2016.

25. Myoung Su Park, Ha Neur Kim, Gyung Jin Bahk. The analysis of food safety incidents in South Korea 1998-2016. Food Control 2017; 81, 196-199. dx. doi.org/https://doi.org/10.1016/j.foodcont.2017.06.013. 
26. Dae Young Kwon, Kyung Rhan Chung. Korean functional foods, chapter 2 Korean diets and their tastes. Boca Raton, CRC Press. 2018. doi.org/https:// doi.org/10.1201/9781315156453

27. Choi YS. Korean cuisine (English and mandarin Chinese edition). CA: Wei Chuans Cooking Publish; 2001.

28. Wookwan. Wookwan's Korean temple food: the road to the taste of enlightenment. South Korea: ICP Inc Publisher, 2018.

29. Kima H, Song M-J, Potter D. Medicinal efficacy of plants utilized as temple food in traditional Korean Buddhism. J Ethnopharmacol. 2006;104:32-46. https://doi.org/10.1016/j.jep.2005.08.041.

\section{Publisher's Note}

Springer Nature remains neutral with regard to jurisdictional claims in published maps and institutional affiliations.

Ready to submit your research? Choose BMC and benefit from:

- fast, convenient online submission

- thorough peer review by experienced researchers in your field

- rapid publication on acceptance

- support for research data, including large and complex data types

- gold Open Access which fosters wider collaboration and increased citations

- maximum visibility for your research: over $100 \mathrm{M}$ website views per year

At BMC, research is always in progress.

Learn more biomedcentral.com/submissions 